\title{
CONDICIONAMENTO OSMÓTICO DE SEMENTES DE MELÃO: ABSORÇÃO DE ÁGUA E GERMINAÇÂO EM DIFERENTES TEMPERATURAS ${ }^{1}$
}

\author{
WARLEY MARCOS NASCIMENTO² E FERNANDO A.S. ARAGÃO ${ }^{3}$
}

\begin{abstract}
RESUMO - A germinação de sementes de melão geralmente é inibida por baixas temperaturas (abaixo de $17^{\circ} \mathrm{C}$ ). $\mathrm{O}$ condicionamento osmótico das sementes pode amenizar o efeito inibitório das baixas temperaturas, melhorando, assim, a germinação e a emergência das plântulas no campo. Sementes de melão foram condicionadas por seis dias, a $25^{\circ} \mathrm{C}$, em solução aerada de $\mathrm{KNO}_{3}(0,35 \mathrm{M})$. A absorção de água pelas sementes foi determinada durante o condicionamento osmótico e durante a germinação. Uma maior germinação, tanto a $17^{\circ} \mathrm{C}$ como a $25^{\circ} \mathrm{C}$, foi observada nas sementes osmoticamente condicionadas. Sementes condicionadas absorveram mais água durante a fase inicial de germinação e germinaram mais rápido do que aquelas não condicionadas.

Termos para indexação: Cucumis melo, estabelecimento de plântulas, termo-inibição.
\end{abstract}

\section{MUSKMELON SEED PRIMING: WATER ABSORPTION AND GERMINATION UNDER DIFFERENT TEMPERATURES}

\begin{abstract}
ABSTACT - Low temperatures (below $17^{\circ} \mathrm{C}$ ) may inhibit muskmelon seed germination. Seed priming may overcome the inhibitory effect of low temperatures and increase germination and seedling establishment in the field. Muskmelon seeds were primed in $\mathrm{KNO}_{3}(0.35 \mathrm{M})$ aerated solution for six days at $25^{\circ} \mathrm{C}$. Water imbibition during seed priming and germination was determined. Higher germination in both temperatures was observed in primed seeds. Primed seeds absorbed more water and germinated faster than unprimed seeds.

Index terms: Cucumis melo, osmotic conditioning, stand establishment.
\end{abstract}

\section{INTRODUÇÃO}

O condicionamento osmótico consiste de uma hidratação controlada das sementes, suficiente para promover atividades pré-metabólicas, sem contudo permitir a emissão da radícula (Heydecker et al., 1973). Em geral, o tratamento consiste em embeber as sementes em uma solução osmótica por um período de tempo determinado, e realizar em seguida, uma secagem das mesmas para o grau de umidade inicial (Nascimento, 1998). O condicionamento osmótico tem sido utilizado principalmente em sementes de hortaliças com o objetivo de melhorar a velocidade de germinação, a uniformidade das plântulas e a porcentagem de germinação, especialmente em

\footnotetext{
${ }_{1}^{1}$ Aceito para publicação em 30.12.2001.

${ }^{2}$ Eng $^{\circ} \mathrm{Agr}^{\circ}$, PhD., Pesquisador Embrapa Hortaliças; Cx. Postal 218, 70359970, Brasília-DF; e-mail: wmn@cnph.embrapa.br

${ }^{3}$ Eng $^{\circ} \mathrm{Agr}^{\circ}$, MSc., Consultor IICA/Embrapa Hortaliças; e-mail: aragao@cnph.embrapa.br
}

condições edafo-climáticas adversas (Bradford, 1986; Khan, 1992 e Parera \& Cantliffe, 1994).

Os efeitos benéficos do condicionamento osmótico na germinação de sementes de melão têm sido previamente reportados (Bradford, 1985; Nerson \& Govers, 1986; Bradford et al., 1988; Passam et al., 1989; Welbaum \& Bradford, 1991; Dhillon, 1995; Olouch \& Welbaum, 1996a; Yeoung et al., 1996 e Nascimento \& West, 1998, 1999 e 2000). Sementes osmoticamente condicionadas geralmente germinam mais rápido do que aquelas não condicionadas. Entretanto, algumas mudanças morfológicas, fisiológicas e bioquímicas que ocorrem nas sementes, decorrentes do tratamento, não estão totalmente elucidadas. Várias hipóteses têm sido atribuídas para explicar o comportamento diferencial destas sementes osmoticamente condicionadas (Bradford, 1986). Tem sido sugerido, por exemplo, que o condicionamento osmótico leva as sementes a um ponto muito próximo da germinação, permitindo, assim, a completa passagem pelas fases I e II de absorção de água, além da extensão da fase II, em que ocorre o 
mecanismo pré-germinativo de reparo das macromoléculas e outras estruturas celulares (Bray, 1995).

O objetivo do trabalho foi comparar a germinação das sementes condicionadas e não condicionadas em duas diferentes temperaturas e verificar a possível associação com a absorção de água pelas sementes.

\section{MATERIAL E MÉTODOS}

O trabalho foi realizado no Laboratório de Sementes do Departamento de Agronomia da Universidade da Flórida, Gainesville, EUA, no ano de 1996. Sementes de melão (Cucumis melo L.) cv. Top Net, SR (Harris Moran Seed Co.) foram condicionadas por seis dias, no escuro, a $25^{\circ} \mathrm{C}$, em solução aerada de $\mathrm{KNO}_{3}(0,35 \mathrm{M})$ (Bradford, 1985). As sementes foram colocadas em frascos de $250 \mathrm{ml}$ com $10 \mathrm{ml} \mathrm{de}$ solução por grama de sementes. A solução osmótica foi trocada a cada dois dias. Após o período de seis dias, as sementes foram lavadas em água corrente, por dois minutos, e colocadas para secar em condições de ambiente do laboratório $\left(24-27^{\circ} \mathrm{C}\right.$ e $50 \%$ de UR) por três dias. Quatro repetições de 50 sementes condicionadas ou não foram colocadas para germinar em placas de petri contendo duas folhas de papel de germinação, umedecidas com $10 \mathrm{ml}$ de água destilada e incubadas em germinadores a 17 e $25^{\circ} \mathrm{C}$, na presença de luz (fluorescente $\left.\sim 26 \mu \mathrm{mol} . \mathrm{m}^{-2} . \mathrm{s}^{-1}\right)$ por 10 e sete dias, respectivamente. A absorção de água pelas sementes ou parte das sementes, tanto durante o condicionamento osmótico, como durante a germinação, foi verificada pela determinação do grau de umidade das sementes, pelo método estufa, a $130^{\circ} \mathrm{C}$ por uma hora (AOSA, 1993). Utilizou-se quatro repetições de 25 sementes. As sementes, após determinados períodos de condicionamento osmótico (a cada hora, durante seis horas), durante a secagem (a cada hora durante três horas) ou durante a germinação $(0,1,3,6,12$, 18 e 24 horas de embebição), foram, ainda, dessecadas sob um microscópio estereoscópico (50 a 60X), utilizando-se um bisturi, em três tecidos: pericarpo (incluiu, neste trabalho, o perisperma e o endosperma, além da testa), cotilédones e eixo embrionário.

Utilizando-se o delineamento inteiramente casualizado, com quatro repetições, foram realizadas análises de variância da regressão, ajustando-se um modelo quadrático para todos os conjuntos de dados. Para os dados de germinação, utilizou-se análise de variância, seguida do teste de Duncan, ao nível de 5\%, para comparação de médias.

\section{RESULTADOS E DISCUSSÃO}

O grau de umidade inicial da semente íntegra foi de 6,5\%. O tecido composto pela testa + perisperma + endosperma (neste trabalho, denominado de pericarpo), cotilédones e o eixo embrionário apresentaram, respectivamente, 6,7; 6,8 e $6,2 \%$ de umidade, contribuindo, em média, com 44,52 e $4 \%$ respectivamente, do peso seco total da semente. A absorção de água pelas sementes de melão durante o condicionamento osmótico, referentes as duas primeiras fases, seguiu o clássico padrão trifásico (Bewley \& Black, 1994). Uma rápida absorção de água foi observada nas primeiras 24 horas (Figura 1), notadamente nas três primeiras horas de embebição (dados não apresentados), sendo a fase II ("lag phase") marcadamente estendida pelo condicionamento osmótico; este tratamento previne a semente de iniciar a fase III de absorção de água.

A absorção de água durante o condicionamento osmótico pelas três partes das sementes comportou-se de maneira diferenciada, observando um acúmulo maior de água no pericarpo, no eixo embrionário e, por último, nos cotilédones (Figura 1). A demora do embrião absorver mais água indica que a testa (ou o perisperma) restringe esta absorção, embora isto não seja devido à impermeabilidade à água promovida por estes tecidos (Welbaum \& Bradford, 1989). Em geral, durante o processo de embebição, o embrião absorve água em uma

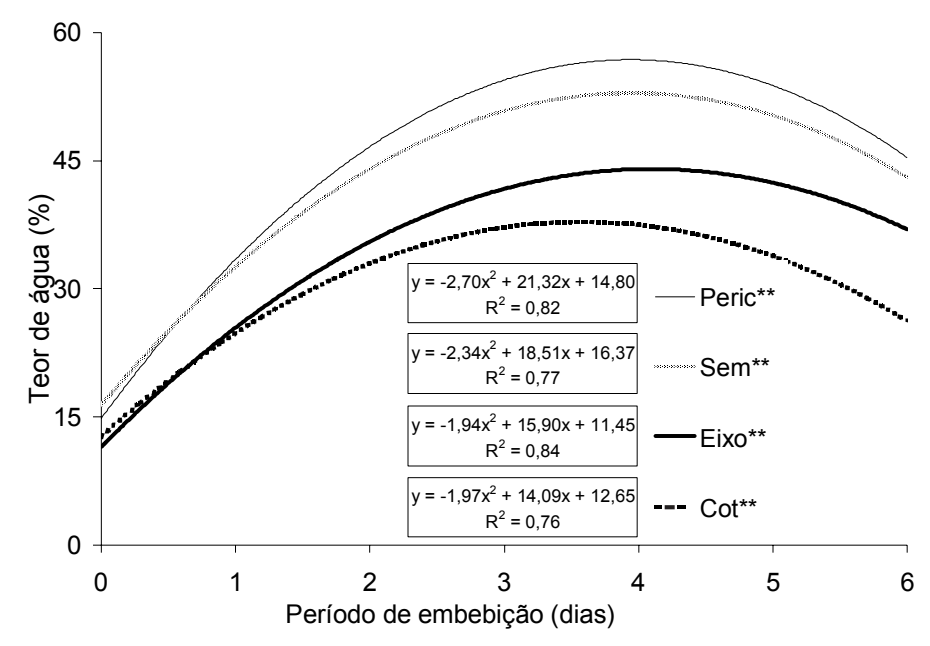

FIG. 1. Absorção de água pelas sementes ou partes das sementes de melão 'Top Net SR' durante o condicionamento osmótico.

**Regressão quadrática significativa a $1 \%$ ). Peric $=$ pericarpo; $\mathbf{S e m}=$ semente; Eixo $=$ eixo embrionário; $\mathbf{C o t}=$ cotilédones. 
velocidade maior que o tecido de reserva (Villela \& MarcosFilho, 1998), neste caso, os cotilédones. No final do período de embebição (seis dias), a umidade das sementes foi de $47,7 \%$. Não foi observada emissão da radícula durante o condicionamento osmótico. Em geral, a umidade das sementes, durante o condicionamento osmótico, é mantida entre 40-45\%, o qual eqüivale aproximadamente a $90-95 \%$ da umidade necessária para proceder a emissão da radícula (Bray, 1995). A umidade das sementes, após três dias de secagem, em ambiente de laboratório, foi de $5,1 \%$. A $17^{\circ} \mathrm{C}$, foi observada uma germinação maior e mais rápida nas sementes osmoticamente condicionadas (Tabela 1). Estes dados corroboram com aqueles observados por diferentes autores, em que os efeitos benéficos do condicionamento osmótico na germinação de sementes de melão ocorreram principalmente em condições de baixas temperaturas (Bradford, 1985; Nerson \& Govers, 1986; Bradford et al., 1988; Passam et al., 1989; Welbaum \& Bradford, 1991; Dhillon, 1995; Olouch \& Welbaum, 1996a e Yeoung et al., 1996). Entretanto, Welbaum \& Bradford (1991) observaram uma melhor resposta à germinação em baixas temperaturas somente quando se utilizou sementes imaturas de melão durante o condicionamento osmótico; sementes totalmente maduras não se beneficiaram do condicionamento. Em temperaturas mais elevadas $\left(25^{\circ} \mathrm{C}\right)$, embora não se tenha observado aumento na porcentagem de germinação, verificou-se, nas sementes osmoticamente condicionadas, uma maior velocidade na germinação (Tabela 1).

A absorção de água pelas sementes, durante as primeiras 24 horas, apresentou incremento com o aumento da temperatura, o que pode ter contribuído para elevar a velocidade de germinação (Figura 2 e Tabela 1). Nas primeiras três horas de embebição não foram observadas diferenças na absorção de água entre as sementes condicionadas e não condicio-

TABELA 1. Germinação de sementes osmoticamente condicionadas e não condicionadas (testemunha) de melão 'Top Net SR' em duas temperaturas.

\begin{tabular}{lcccc}
\hline \multirow{2}{*}{ Tratamento } & \multicolumn{4}{c}{ Germinação $(\%)$} \\
\cline { 2 - 5 } & \multicolumn{4}{c}{ Temperatura $\left({ }^{\circ} \mathrm{C}\right)$} \\
\cline { 2 - 5 } & \multicolumn{3}{c}{17} & 25 \\
\hline Osmoticamente condicionada & 87 & $(98,4)$ & 89 & $(38,6)$ \\
Testemunha & 72 & $(158,5)$ & 91 & $(54,5)$ \\
\hline Significância & $*$ & $*$ & ns & $*$ \\
\hline ns, $*=$ não significante, significante respectivamente, a $\mathrm{P}=0.05$, Teste de \\
Duncan. \\
Números entre parênteses significam horas para 50\% de germinação.
\end{tabular}

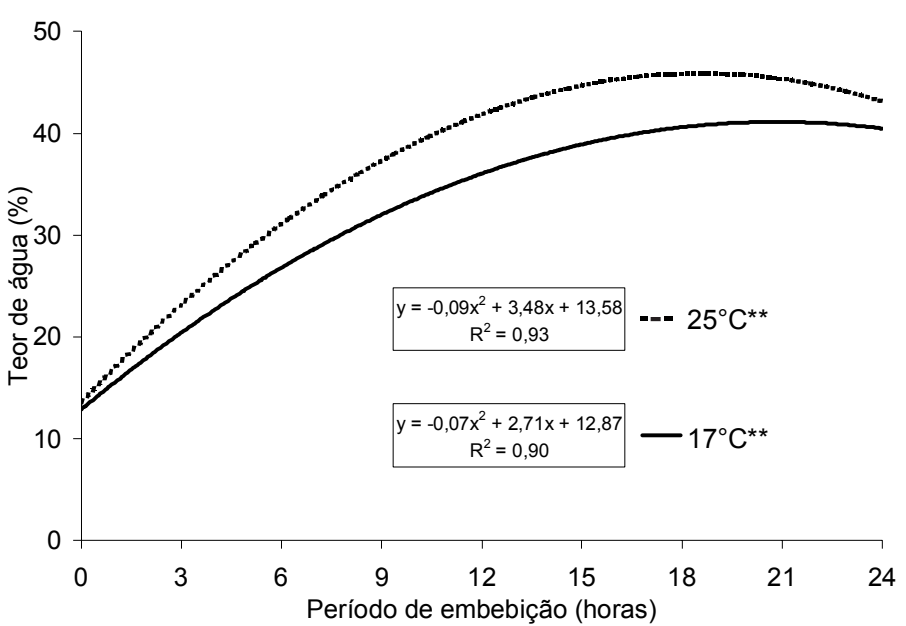

FIG. 2. Absorção de água pelas sementes de melão 'Top Net SR' durante as primeiras 24 horas de germinação e em duas temperaturas de incubação.

(** Regressão quadrática significativa a 1\%).

nadas, tanto a 17 como a $25^{\circ} \mathrm{C}$ (Figuras 3 e 4). Entretanto, após três horas de embebição, a absorção de água pelas sementes osmoticamente condicionadas foi, em média, superior a daquelas não condicionadas. Isto poderia influenciar direta ou indiretamente a velocidade de germinação das sementes sugerindo, assim, a razão pela qual as sementes osmoticamente condicionadas germinam mais rápido do que aquelas não condicionadas. Em adição a isto, verificou-se, principalmente a $17^{\circ} \mathrm{C}$ (Figura 5), que o eixo embrionário das semen-

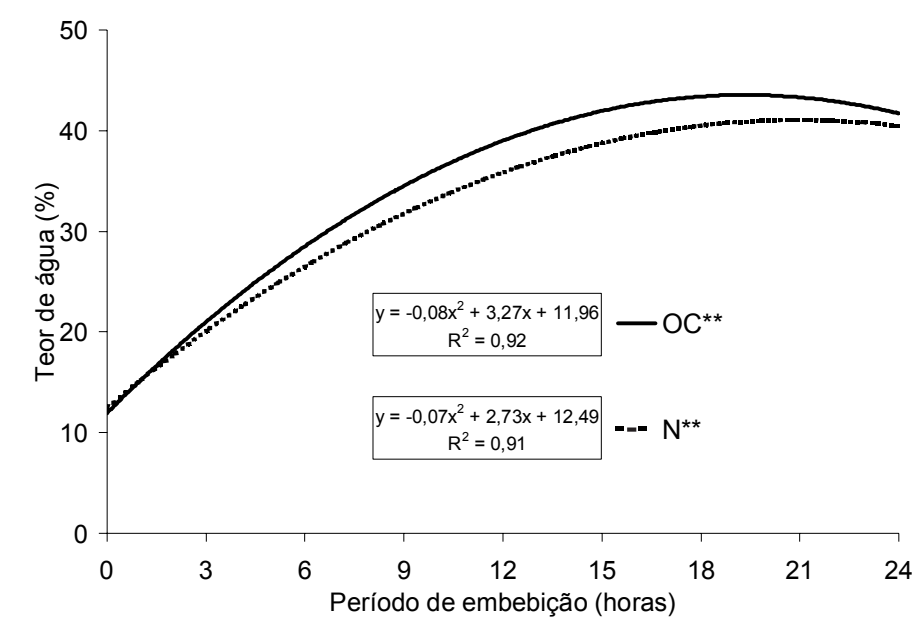

FIG. 3. Absorção de água pelas sementes de melão 'Top Net SR' osmoticamente condicionadas (OC) ou não condicionadas $(\mathrm{N})$ durante as primeiras 24 horas de germinação e incubadas a $17^{\circ} \mathrm{C}$.

** Regressão quadrática significativa a $1 \%$ ). 


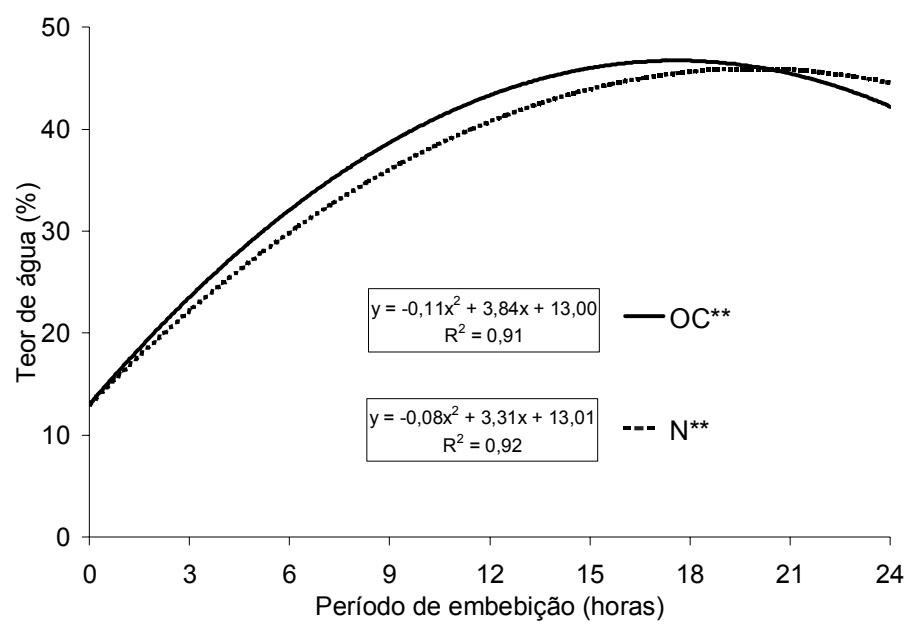

FIG. 4. Absorção de água pelas sementes de melão 'Top Net SR' osmoticamente condicionadas (OC) ou não condicionadas $(\mathrm{N})$ durante as primeiras 24 horas de germinação e incubadas a $25^{\circ} \mathrm{C}$.

(** Regressão quadrática significativa a $1 \%$ ).

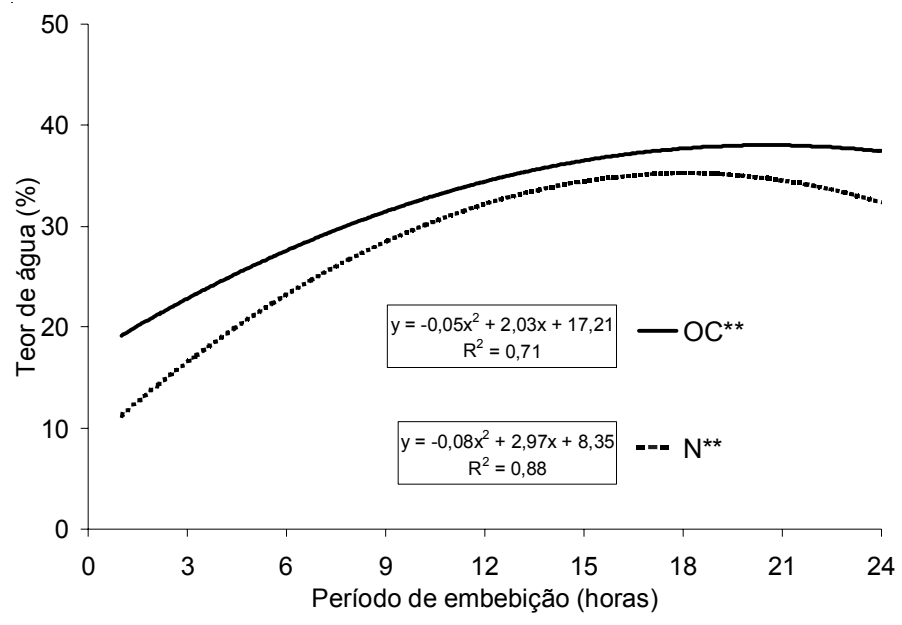

FIG. 5. Absorção de água pelo eixo embrionário das sementes de melão Top Net SR' osmoticamente condicionadas (OC) ou não condicionadas $(\mathrm{N})$ durante as primeiras 24 horas de germinação e incubadas a $17^{\circ} \mathrm{C}$.

** Regressão quadrática significativa a $1 \%$.

tes condicionadas absorveu mais água do que aqueles das sementes não condicionadas. Nas três primeiras horas, por exemplo, o eixo embrionário das sementes osmoticamente condicionadas absorveu cerca de $50 \%$ a mais de água do que aquele proveniente de sementes não condicionadas.

Sementes de melão germinam quando a turgescência no eixo embrionário excede o valor limite para o crescimento radicular (Welbaum et al., 1995). Assim, sementes condicio- nadas germinam mais rápido, pois atingem este valor limite mais cedo do que aquelas não condicionadas (Olouch \& Welbaum, 1996a). Uma possível hipótese pela qual as sementes osmoticamente condicionadas de melão germinam melhor a $17^{\circ} \mathrm{C}$ seria o aumento na velocidade de germinação destas sementes amenizando, assim, o efeito deletério de baixas temperaturas. Em uma outra possível hipótese, as sementes osmoticamente condicionadas de melão poderiam suportar melhor o efeito negativo das baixas temperaturas na germinação devido ao fato que estas, durante o metabolismo de pré-germinação, passaram por uma temperatura mais elevada $\left(25^{\circ} \mathrm{C}\right)$ durante o condicionamento osmótico. O condicionamento osmótico estende a "lag phase" de absorção de água e este período prolongado nesta fase II poderia promover um mecanismo específico (aumento de uma atividade enzimática, por exemplo) necessário à germinação em condições de baixas temperaturas. Em adição, o comprimento da fase II é dependente da temperatura do meio (Bewley \& Black, 1994). Assim, a germinação a $25^{\circ} \mathrm{C}$, durante o condicionamento osmótico, procedeu em um nível adequado para favorecer a germinação em temperaturas baixas. Outros eventos citados que ocorrem durante o condicionamento osmótico de sementes de melão, e que poderiam favorecer a germinação foram o enfraquecimento do perisperma, permitindo a penetração da radícula (Oluoch \& Welbaum, 1996b), o aumento da síntese de $\beta$-tubulina e o aumento da atividade de endo- $\beta$-mananase (Olouch et al., 1999).

Técnicas que permitem um monitoramento da distribuição e movimentação de água nas sementes devem ser incrementadas e um maior entendimento do mecanismo do condicionamento osmótico em sementes de melão poderá auxiliar na melhoria do estabelecimento de plântulas no campo, principalmente em condições edafo-climáticas adversas.

\section{CONCLUSÕES}

- O condicionamento osmótico aumentou a velocidade de germinação a $17^{\circ} \mathrm{C}$;

- em baixas temperaturas, o eixo embrionário das sementes osmoticamente condicionadas absorve água mais rapidamente.

\section{REFERÊNCIAS}

AOSA - ASSOCIATION OF OFFICIAL SEED ANALYSTS. Rules for testing seeds. Journal of Seed Technology, Bettsville, v.16, n.3, p.1-113, 1993. 
BEWLEY, J.D. \& BLACK, M. Seeds: physiology of development and germination. 2ed. New York: Plenum Press, 1994. 445p.

BRADFORD, K.J. Seed priming improves germination and emergence of cantaloupe at low temperature. HortScience, Alexandria, v.20, n.3, p.598, 1985.

BRADFORD, K.J. Manipulation of seed water relations via osmotic priming to improve germination under stress conditions. HortScience, Alexandria, v.21, n.5, p.1105-1112, 1986.

BRADFORD, K.J.; MAY, D.M.; HOYLE, B.J.; SHIBINSKI, Z.S.; SCOTT, S.J. \& TYLER, K.B. Seed and soil treatments to improve emergence of muskmelon from cold or crusted soils. Crop Science, Madison, v.28, n.6, p.1001-1005, 1988.

BRAY, C.M. Biochemical processes during the osmopriming of seeds. In: KIGEL, J. \& GALILI, G. (eds.). Seed development and germination. New York: Marcel Dekker, Inc., 1995. p.767789 .

DHILLON, N.P.S. Seed priming of male sterile muskmelon (Cucumis melo L.) for low temperature germination. Seed Science and Technology, Zürich, v.23, n.3, p.881-884, 1995.

HEYDECKER, W.; HIGGIS, J. \& GULLIVER, R.L. Accelerated germination by osmotic treatment. Nature, London, v.246, n.5427, p.42-44, 1973.

KHAN, A.A. Preplant physiological seed conditioning. Horticultural Reviews, Westport v.13, p.131-181, 1992.

NASCIMENTO, W.M. Condicionamento osmótico de sementes de hortaliças: potencialidades e implicações. Horticultura Brasileira, Brasília, v.16, n.2, p.106-109, 1998.

NASCIMENTO, W.M. \& WEST, S.H. Priming and seed orientation affect seed coat adherence and seedling development of muskmelon transplants. HortScience, Alexandria, v.33, n.5, p.847-848, 1998

NASCIMENTO, W.M. \& WEST, S.H. Muskmelon transplant production in response to seed priming. HorTechnology, Alexandria, v.9, n.1, p.53-55, 1999.

NASCIMENTO, W.M. \& WEST, S.H. Drying during muskmelon (Cucumis melo L.) seed priming and its effects on seed germination and deterioration. Seed Science and Technology,
Zürich, v.8, n.1, p.211-215, 2000.

NERSON, H. \& GOVERS, A. Salt priming of muskmelon seeds for low-temperature germination. Scientia Horticulturae, Amsterdam, v.28, n.1/2, p.85-91, 1986.

OLUOCH, M.O. \& WELBAUM, G.E. Effect of postharvest washing and post-storage priming on viability and vigour of six-yearold muskmelon (Cucumis melo L.) seeds from eight stages of development. Seed Science and Technology, Zürich, v.24, n.1, p.195-209, 1996a.

OLUOCH, M.O. \& WELBAUM, G.E. Viability and vigor of osmotically primed muskmelon seeds after nine years of storage. Journal of the American Society for Horticultural Science, Alexandria, v.121, n.3, p. 408-413, 1996 b.

PARERA, C.A. \& CANTLIFFE, D.J. Presowing seed priming. Horticultural Reviews, Westport, v.16, p.109-139, 1994.

PASSAM, H.C.; KARAVITES, P.I.; PAPANDREOU, A.A.; THANOS, C.A. \& GEORGHIOU, K. Osmoconditioning of seeds in relation to growth and fruit yield of aubergine, pepper, cucumber and melon in unheated greenhouse cultivation. Scientia Horticulturae, Amsterdam, v.38, n.3/4, p.217-216, 1989.

VILLELA, F.A. \& MARCOS-FILHO, J. Estados energéticos e tipos de água na semente. Revista Brasileira de Sementes, Curitiba, v.20, n.2, p.317-321, 1998.

WELBAUM, G.E. \& BRADFORD, K.J. Water relations of seed development and germination in muskmelon (Cucumis melo L.). V. Water relations of imbibition and germination. Plant Physiology, Lancaster, v.92, n.4, p.1046-1052, 1989.

WELBAUM, G.E. \& BRADFORD, K.J. Water relations of seed development and germination in muskmelon (Cucumis melo L.). VI. Influence of priming on germination responses to temperature and water potential during seed development. Journal of Experimental Botany, London, v.42, n.236, p.393-399, 1991.

YEOUNG, Y.R.; WILSON JR., D.O. \& MURRAY, G.A. Germination performance and loss of late-embryogenesisabundant (LEA) proteins during muskmelon seed priming. Seed Science and Technology, Zürich, v.24, n.3, p.429-439, 1996.

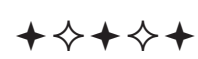

